\title{
CONSTRUÇÃO DE UMA TECNOLOGIA VISUAL PARA AO TRATAMENTO DE INFILTRAÇÕES E EXTRAVASAMENTOS RELACIONADOS AO USO DE MEDICAMENTOS E SOLUÇÕES EM CRIANÇAS HOSPITALIZADAS
}

\author{
$\underline{\text { Júlia de Paula Silva }}^{1}$;_Luciano Marques dos Santos ${ }^{2}$; Katharinne de Jesus Nunes ${ }^{3}$; Paula \\ Horrana Carvalho Silva ${ }^{4}$ \\ ${ }^{1}$ Graduanda em Enfermagem, Universidade Estadual de Feira de Santana, Voluntária (PIBITI) do NUDES, e-mail: \\ silvapaulladejulia@gmail.com \\ ${ }^{2}$ Orientador. Departamento de Saúde, Universidade Estadual de Feira de Santana, Pesquisador do Núcleo Interdisciplinar de \\ Estudos sobre Desigualdades em Saúde (NUDES), e-mail: lucmarxenfo@ hotmail.com: \\ lucmarxenfo@hotmail.com \\ ${ }^{3}$ Participante do NUDES, Departamento de Saúde, Universidade Estadual de Feira de Santana, e-mail: \\ silvapaulladejulia@gmail.com katharinnenunes@yahoo.com.br \\ ${ }^{4}$ Participante do NUDES, Departamento de Saúde, Universidade Estadual de Feira de Santana, e-mail: \\ paulahorrana.uefs@yahoo.com.br
}

Palavras-chave: terapia intravenosa, punção intravenosa periférica, cartilha da família

\section{INTRODUÇÃO}

A terapia intravenosa (TIV) compreende um dos procedimentos mais utilizados como forma de tratamento em crianças portadoras de doenças crônicas e agudas (PETERLINI; CHAUD; PEDREIRA, 2003). Considerando a terapia intravenosa um processo invasivo e muito complexo, é necessário que existam muitos cuidados na sua instalação e manutenção (HARADA; RÊGO, 2005). Para que a TIV seja instituída é necessário a realização da punção intravenosa periférica (PIP), que corresponde à inserção de um dispositivo na no vaso sanguíneo (MODES et al., 2011). Entretanto, mesmo sendo uma via segura, a infusão de medicamentos ou soluções através da via intravenosa pode potencializar a ocorrência de eventos adversos.

Os eventos adversos (EA) são ocorrências indesejáveis, porém preveníveis, de natureza danosa ou prejudicial que comprometem a segurança do paciente que se encontra sob os cuidados dos profissionais de saúde (NASCIMENTO, 2008). Os EA são considerados infecciosos quando estão relacionadas à tromboflebite séptica, endocardite, bacteremia ou fungemia, e infecções metastáticas (osteomielites, artrites, etc) resultantes da disseminação hematogênica a partir do cateter colonizado, e os não infecciosos quando se relacionam com infiltração, extravasamento, saída acidental do dispositivo, obstrução, entre outros (PAULA, 2011).

A infiltração, a qual pode ser definida como o deslocamento da ponta do cateter da veia, provocando a saída de medicamento ou solução não vesicante ao redor do tecido (espaço extravascular). Solução ou medicamento não vesicante pode ser entendido como substâncias que não geram graves lesões ao tecido vascular (HARADA; RÊGO, 2005; HARADA; RÊGO, 2011). Por outro lado, o extravasamento é definido como a infiltração de fármacos vesicantes, com características semelhantes à infiltração, pois o mecanismo de ação é similar. Entretanto, no caso do extravasamento, o fármaco pode provocar graves lesões teciduais, com a formação de bolhas e necrose (PHILLIPS, 2001). Estes eventos adversos provocam lesões que vão de leve a grave, variando desde a formação de bolhas até ulcerações, prolongando assim o tempo de hospitalização da criança e causando danos severos. Assim, diante destas lesões, os trabalhadores da saúde precisam realizar cuidados especiais seguros que possam minimizar os danos decorrentes destes eventos adversos, a exemplo dos cuidados no local da infiltração ou do extravasamento.

Neste sentido, é necessária a utilização de tecnologias que possam auxiliar os trabalhadores da saúde atuantes no cuidado de crianças hospitalizadas que necessitam de terapias intravenosas e infusionais, que apresentam infiltrações e/ou extravasamentos, visando a prevenção o 
cuidado local na vigência deste eventos adversos e para a promoção da segurança deste pacientes. O algoritmo será um instrumento facilitador para melhor visualização do tratamento de infiltração e extravasamento e consequentemente avanços na prática clínica e melhora da situação da criança hospitalizada.

Entretanto, ao fazer o levantamento do estado da arte sobre infiltrações, extravasamentos e tratamento destes eventos adversos, na Biblioteca Virtual de Saúde, PubMED e Science Direct, no período de janeiro a maio de 2015, utilizando os descritores Enfermagem Pediátrica, Criança, Criança Hospitalizada, cateterismo periférico, infusões intravenosas, efeitos adversos e Extravasamento de Materiais Terapêuticos e Diagnósticos foram encontrados dois artigos que abordavam esta temática. Assim, observando a escassez de estudos referentes à temática, questionou-se: É construir uma tecnologia didática e instrucional para orientar os trabalhadores da saúde no tratamento de infiltrações e extravasamentos em crianças hospitalizadas? Esta tecnologia possui validade de aparência, conteúdo e aplicabilidade prática?

\section{MÉTODOS}

Trata de um estudo metodológico, do tipo produção tecnológica. Para a elaboração da tecnologia visual foram coletados, lidos e fichados 16 artigos que continham informações sobre o tratamento de infiltrações e extravasamentos decorrentes de medicamentos e/ou soluções intravenosos. Os artigos foram coletados na Biblioteca Virtual em Saúde, PUBMED e Scienc Direct, sendo utilizados os seguintes descritores: Enfermagem pediátrica, criança, criança hospitalizada, cateterismo periférico, infusões intravenosas, efeitos adversos e extravasamento de materiais terapêuticos e diagnósticos. Os artigos foram selecionados através dos seguintes critérios: ano de publicação superior a 2004, publicação na integra dos idiomas português, inglês e espanhol, artigos originais e que contenham informações sobre características a natureza dos medicamentos. Foram excluídos os seguintes artigos: disponíveis parcialmente nas bases de dados e que estejam no prelo.

Após a seleção dos artigos, foi realizada a leitura na integra dos mesmos, buscando identificar as seguintes informações: autoria, ano de publicação, periódico de publicação, objetivos, metodologia e principais resultados. Estes dados foram transportados para uma ficha e a seguir foram analisados partindo de suas convergências e divergências, sendo elaborado um algoritmo contendo os cuidados que deverão ser adotados diante da infiltração e extravasamento.

\section{RESULTADOS}




\section{TRATAMENTO DE INFILTRAÇÃO E EXTRAVASAMENTO}

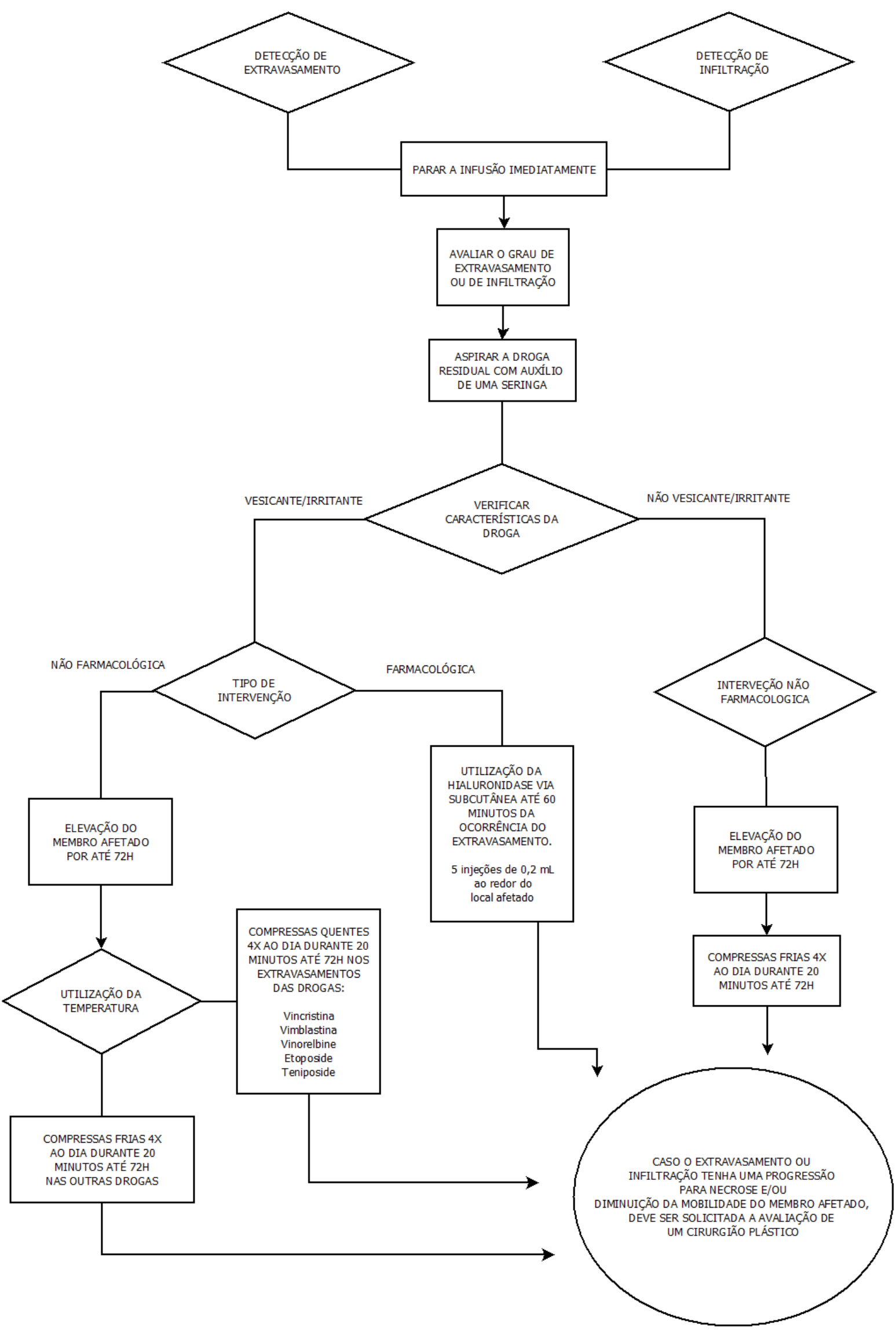




\section{CONCLUSÃO}

Os algoritmos são instrumentos facilitadores que gerencia a qualidade do serviço e é utilizado para tomadas de decisões para melhoria da prática clínica do tratamento de infiltração e extravasamento em crianças hospitalizadas. Este recurso foi construído a partir de evidências clínicas, de fácil leitura e utilização para que a equipe de enfermagem tenha uma maior dinamicidade na sua prática. É necessário realizar a validação do conteúdo, aparência e clínica com especialistas da área.

\section{REFERÊNCIAS}

HARADA, M. J. C. S.; REGO, R. C. Manual de terapia intravenosa em pediatria. São Paulo: Lisanti, 2005.

HARADA, M. J. C. S.; RÊGO, R. C. Complicações locais da terapia intravenosa. In: HARADA, M. J. C. S.; PEDREIRA, M. L. G. Terapia intravenosa e infusões. São Caetano do Sul, SP: Yendis Editora, 2011. p. 419-43.

MODES, P. S. S. A. et al. Cuidados de enfermagem nas complicações da punção venosa periférica em recém-nascidos. Rev. Rene, v. 12, n. 2, p. 324-332, abr./jun. 2011.

NASCIMENTO, C. C. P. et al. Indicadores de resultados da assistência: análise dos eventos adversos durante a internação hospitalar. Rev Latino-am Enfermagem 2008 julho-agosto; 16(4). Disponível em: < http://www.scielo.br/pdf/rlae/v16n4/pt_15.pdf>. Acesso em: $20 \mathrm{de}$ maio de 2015

PAULA, D. H. G. de. Eventos adversos relacionados ao acesso intravenoso na terapia de endocardite infecciosa no instituto nacional de cardiologia de 2009 a 2010. 2010. $105 \mathrm{f}$. Dissertação (Mestrado em Cardiologia e Infecção)- Pós- Graduação em Pesquisa Clínica em Cardiologia e Infecção, Fundação Oswaldo Cruz, Rio de Janeiro. 2010. Disponível em: < http://www.abeneventos.com.br/16senpe/senpe-trabalhos/files/0241.pdf> Acesso em 19 de maio de 2015.

PHILLIPS, L. D. Manual de Terapia Intravenosa. 2. ed. Porto Alegre: Ed. Artmed, 2001. PETERLINI, M. A. S.; CHAUD, M. N.; PEDREIRA, M. L. G. Órfãos da terapia medicamentosa: a administração de medicamentos por via intravenosa em crianças hospitalizadas. Rev Latino-Am Enfermagem. v. 11, n. 1, p. 88-95. 2003; 